\title{
ENFERMEDAD DE GAUCHER, UN ABORDAJE TERAPÉUTICO MODERNO
}

María Helena Solano., Carlos Ramírez C., Lucía Parra., José Loboguerrero.*

\section{Resumen}

La enfermedad de Gaucher es un trastorno del almacenamiento lisosomal o enfermedad de depósito, para la cual sólo había terapia paliativa hasta 1991. El desarrollo de medicamentos "huérfanos", gracias a la subvención estatal en países desarrollados, permitió la producción de una enzima de reemplazo (imiglucerasa) que ha transformado por completo el panorama de la calidad de vida de los pacientes en edad pediátrica y, en forma sensible, el de los adultos.

Se describe el primer caso tratado en Colombia y su seguimiento a lo largo de cinco años. Los efectos adversos del tratamiento son escasos y leves, pero el inmenso costo constituye una limitación en especial en nuestros países. El profundo conocimiento de la genética y la bioquímica de la enfermedad condujo al desarrollo de una terapia eficaz y otras afecciones deberán seguir el mismo rumbo.

\section{Introducción}

La enfermedad de Gaucher (EG) es una enfermedad de depósito, rara y hereditaria, ocasionada por la deficiencia parcial o total de la enzima beta glucocerebrosidasa; dicha molécula metaboliza los glucocerebrósidos presentes en las células del sistema reticuloendotelial y su deficiencia produce la acumulación de este complejo lipídico. A consecuencia de ello, las células reticuloendoteliales adquieren una morfología especial que consiste en un citoplasma abundante y filamentos, en forma de "papel arrugado". Tales células fueron descritas en 1882 por el médico francés Phillip Charles Ernest Gaucher, de quien reciben su nombre (células de Gaucher).

La acumulación de glucosilceramidas o glucocerebrósidos en los lisosomas de los tejidos que contienen macrófagos, los cuales no pueden ser separados en glucosa y ceramida para su metabolismo ulterior, produce el crecimiento y la disfunción de varios órganos: hígado, bazo, hueso, medula ósea y pulmones.

Las manifestaciones de la enfermedad comprenden hepatoesplenomegalia, pancitopenia, dolor óseo, frac-

* Servicio de Hematología, Hospital de San José, Fundación Universitaria de Ciencias de la Salud. Bogotá, D.C. turas patológicas y deformidades. Se distinguen tres tipos o formas clínicas: no neuronopático o tipo 1; tipo 2 o neuronopático agudo y tipo 3 o neuronopático subagudo (Tabla 1).

Hasta el momento, se han identificado varias mutaciones relacionadas con el desarrollo de la EG (Tabla 2).

\section{Descripción del caso clínico}

Paciente varón de 54 años de raza blanca, originario del departamento de Santander. A los 29 años se le diagnosticó EG tipo 1, cuando presentó hepatitis viral por mononucleosis infecciosa de evolución atípica con persistencia de transaminasas elevadas, anemia y esplenomegalia moderada. El mielograma y la biopsia de medula ósea evidenciaron infiltración por células de Gaucher.

Un año antes le habían practicado reemplazo de la cadera por necrosis avascular de la cabeza del fémur. La revisión retrospectiva de la patología femoral mostró células espumosas.

En los 15 años siguientes desarrolló deterioro progresivo con visceromegalias gigantes, anemia, leucopenia global, trombocitopenia, alteración de las pruebas de función hepática y limitación para la marcha por disfunción de la prótesis de la cadera. El paciente recịía tratamiento sintomático. 


\section{Características de los tipos de enfermedad de Gaucher}

$\begin{array}{llll} & \text { Tipo 1 } & \text { Tipo } 2 & \text { Tipo 3 } \\ \text { Edad de presentación } & \text { Infancia y adulto } & \text { Infancia } & \text { Infancia } \\ \text { Esplenomegalia } & \text { Ligera a severa } & \text { Moderada } & \text { Ligera a severa } \\ \text { Hematomegalia } & \text { Ligera a severa } & \text { Moderada } & \text { Ligera a severa } \\ \text { Enfermedad ósea } & \text { Ausente a severa } & \text { No } & \text { Moderada a severa } \\ \begin{array}{llll}\text { Compromiso del } \\ \text { sistema nervioso central }\end{array} & \text { No. } & \text { Presente } & \text { Presente precoz } \\ \text { Etnia } & \text { Todas las razas } & \text { Todas } & \text { Todas } \\ \text { Judíos Ashkenazi } & & \text { Norrbotianos } \\ \text { Frecuencia } & \begin{array}{l}\text { 1/60.000 } \\ \text { Judíos: } 1 / 500\end{array} & <1 / 100.000 & <1 / 50.000\end{array}$

Tabla 1
Entonces, se comenzó tratamiento con alglucerasa intravenosa a dosis de $40 \mathrm{U} / \mathrm{kg} / \mathrm{do}-$ sis (2.800 unidades) en infusión de dos horas cada 15 días. A los tres años de terapia continua se cambió a imiglucerasa, enzima de origen recombinante, en las mismas dosis en forma ininterrumpida hasta la fecha. En 1997 sufrió una fractura de la cadera derecha, de origen traumático, que requirió cambio de la prótesis, cirugía de alta complejidad con reconstrucción del acetábulo e injertos óseos. El postoperatorio tardío se complicó con anemia hemolítica autoinmune, secundaria a cefalosporinas.

El paciente ha completado cinco años de reemplazo enzimático. Durante los primeros meses no hubo cambios en las variables hematológicas. Al final del primer año se determinó el hematocrito, la hemoglobina y el recuento leucocitario. (Figura 1).

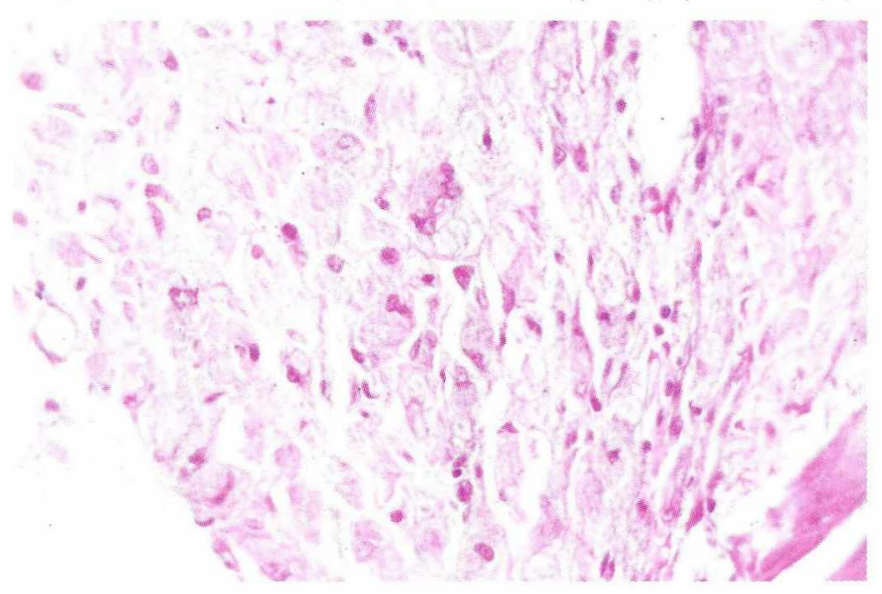

Figura 1. Biopsia ósea que muestra extenso reemplazo de la hematopoyesis normal por histiocitos tipo células de Gaucher PAS positivas. (tinción de Ácido Peryódico de Schiff-PAS). a una mutación infrecuente aún no determinada. 
La trombocitopenia persiste, aunque ha incrementado tres veces su valor basal (Figura 2).

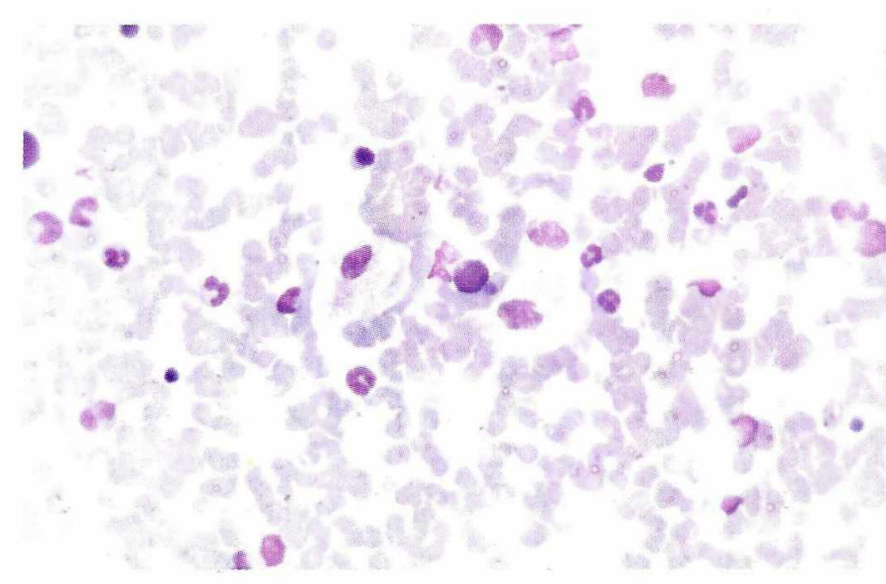

Figura 2. Mielográma: extendido con presencia de histiocitos de citoplasma amplio, con aspecto fibrilar y estriado, ligeramente basófilo, con núcleos pequeños (tinción de Wright).

A los 18 meses se normalizaron las transaminasas y los tiempos de coagulación y al cabo de 24 meses, también se normalizó la fosfatasa ácida. El volumen visceral disminuyó $50 \%$ en dos años y $25 \%$ en los siguientes tres años. El impacto de la terapia sobre la calidad de vida ha sido dramático, pues de una limitación marcada inicial, debida a distensión abdominal, astenia, adinamia, compromiso para la marcha y caquexia, el paciente aumentó su capacidad gástrica, recuperó peso, puede dormir en decúbito prono, está en capacidad de subir escaleras y practicar la natación. Además, ha mejorado su rendimiento laboral y su calidad de vida familiar y social. La tolerancia al medicamento ha sido excelente, sin ningún efecto secundario indeseable.

\section{Discusión}

El diagnostico de la EG, se sospecha por los hallazgos clínicos y la determinación de células de Gaucher en biopsias; sin embargo la confirmación se realiza mediante la determinación de la actividad de la enzima beta glucosidasa en leucocitos circulantes y con estudios genéticos, que caracterizan el tipo de mutación.

Aunque las células de Gaucher son fáciles de identificar en los cortes histológicos, hay células de aspecto espumoso similar o células de pseudogaucher que se encuentran en enfermedades neoplásicas o inflamatorias crónicas. Por esta razón la determinación enzimática es siempre necesaria.

La severidad de la enfermedad y el compromiso de órganos se establece por las anormalidades en diversas pruebas. Los estudios hematológicos incluyen cuadro hemático, velocidad de sedimentación, fosfatasa alcalina y fracción no prostática de la fosfatasa ácida. Las pruebas viscelares comprenden la medición volumétrica del hígado y el bazo, mediante tomografía axial computadorizada (TAC) o resonancia magnética nuclear (RMN). Los estudios óseos necesarios incluyen radiografías del fémur, húmero y columna vertebral, RMN del fémur (para evaluar el reemplazo de médula ósea) y densitometría ósea por absorción dual de rayos $\mathrm{X}$ (DEXA), para determinar el riesgo de fracturas.

Hasta hace diez años el tratamiento se reducía a medidas paliativas que incluían suplementos de hierro, calcio y algunas vitaminas, terapia transfusional, esplenectomía, andrógenos, eritropoyetina, analgésicos y reemplazos articulares. El transplante de médula ósea como método curativo fracasó por las complicaciones y la morbimortalidad inherentes a esta modalidad terapéutica.

De ser una enfermedad huérfana, sin tratamiento específico, pero con una fisiopatogenia bien estudiada, pasó a beneficiarse de una terapia revolucionaria con los adelantos de la biotecnología.

La terapia de reemplazo enzimático (TRE) apareció alrededor de 1991 con una enzima derivada de la placenta humana (alglucerasa), aplicada por vía intravenosa. En los últimos años la enzima (imiglucerasa) es obtenida por tecnología recombinante y ofrece muchas ventajas sobre la anterior.

En la actualidad hay casi 3.000 pacientes con TRE en el mundo que han sido seguidos por más de diez años. La dosis recomendada es de 40 a 60 unidades por kilo de peso cada 15 días, en infusión intravenosa de dos a cuatro horas y la suplencia es permanente debido al carácter genético de la enfermedad.

Dado que la afección tiene variabilidad clínica, debe realizarse una evaluación y decisión individual para la TRE, en la cual es preciso tener en cuenta los factores 
de alto riesgo de compromiso multisistémico y de progresión de la enfermedad, como ocurre en el paciente pediátrico, la enfermedad esquelética, el deterioro de la calidad de vida, las hemorragias, la dependencia transfusional, la anemia y la hipertensión portal.

El control de la terapia se basa en las recomendaciones del Internacional Collaborative Gaucher Group (ICGG). Este se estableció en 1991 con el fin de acumular la experiencia mundial y asistir a los médicos en el manejo de sus pacientes. Los hematólogos del Hospital de San José están inscritos en este registro.

El monitoreo del tratamiento está basado en cuatro áreas que tienen evaluaciones mensuales, trimestrales o anuales de acuerdo con los órganos comprometidos. Para establecer el compromiso hematológico se requiere: cuadro hemático, velocidad de sedimentación globular, fosfatasa alcalina y transaminasas. Se realiza evaluación antes de iniciar la terapia y después, cada tres meses. Para el compromiso visceral: medición volumétrica del hígado y el bazo por TAC o RNM utilizando una misma tecnología y aparato para determinar la evolución. Debe efectuarse en la fase inicial y luego determinaciones anuales. Así mismo, la valoración del compromiso esquelético amerita RMN de fémur cada año y la evaluación de calidad de vida (QOL-SF 36) debe determinarse cada seis meses, mediante una escala validada de funcionamiento social y bienestar, que contempla 36 preguntas para ser respondidas por el paciente en diez minutos.

\section{Comentario}

LaEG está incluida entre las 5.000 enfermedades raras (NORD) y la enzima de reemplazo específica: la imiglucerasa es un medicamento "huérfano". En Estados Unidos se considera como tal a todo fármaco que se utiliza en menos de 200.000 pacientes, mientras que en la Unión Europea, el límite es de 3.000 pacientes por país.

Tanto los enfermos como las familias con este tipo de afección están condenados al sufrimiento y a la desesperanza porque los hospitales, las universidades y los laboratorios farmacéuticos muestran poco interés en su investigación, debido a la escasa cantidad de casos y la baja retribución económica para la investigación, lo cual conduce a una severa limitación de los recursos econó- micos. Los países desarrollados tienen en su legislación diferentes incentivos para motivar a las comunidades científicas en la investigación de estas áreas.

LaEG como error innato del metabolismo ha sido modelo en lainvestigación y fuente de invaluables enseñanzas.

En Latinoamérica la enfermedad se ha descrito en todas las etnias. La prueba enzimática se realiza en Argentina, Brasil, Chile, México, Perú, Venezuela y Colombia, pero el análisis genético solo está disponible en Argentina, Brasil y México. Las principales mutaciones encontradas son: N370S, 84GG, IVS2 y L444P.

Brasil registra el mayor número de pacientes tratados (140 de 160 diagnosticados) y en segundo lugar está Argentina con 80 pacientes tratados, de 114 confirmados. Los países restantes registran menos de treinta casos y en varios de ellos no hay acceso al diagnóstico ni a la terapia. En Colombia, se han confirmado 30 casos de los cuales 10 están en terapia. En todos los países la mayoría de los enfermos son de edad pediátrica. El rango de dosis utilizada oscila entre 30 a 60 unidades por kilo/dosis.

Los deseos intensos de vivir y la tenacidad de este paciente, motivaron a los miembros del nuestro servicio de hematología a interesarnos por la enfermedad y recibimos entrenamiento en Boston, Nueva York y Guadalajara en los aspectos médicos y de laboratorio. En 1995 se implantó la prueba de actividad de la beta glucosidasa, lo que permitió confirmar la mayoría de los casos recolectados y administrar la terapia de reemplazo enzimático por primera vez en Colombia en este enfermo. Los estudios genéticos se adelantan en el Instituto de Errores Innatos del Metabolismo de la Pontificia Universidad Javeriana de Bogotá D.C.

Los resultados de la terapia de reemplazo enzimático en nuestro paciente corresponden con los descritos en la literatura para adultos con severos estigmas de la enfermedad. La evolución en los niños, en general, es más rápida. La remisión de los síntomas es evidente hacia los seis meses de terapia aunque en los primeros meses hay sensación subjetiva de bienestar y disminución de la astenia y la adinamia. La mejoría del hematocrito, la hemoglobina y el recuento leucocitario comienza hacia el tercer 
mes de tratamiento y los valores alcanzan cifras normales hacia el segundo año, con una respuesta sostenida. Se desconoce la causa por la cual las plaquetas tienen una respuesta variable y más lenta; pero su incremento alcanza el doble del valor basal después de los 24 meses.

Las alteraciones bioquímicas muestran normalización al cabo de dos años, mientras que la reducción de las visceromegalias es de cerca del $25 \%$ por año, después del primer año. Por su parte, las lesiones óseas son de lenta remisión. y muchos pacientes tienen enfermedad ósea severa con destrucción y secuelas graves que ameritan tratamiento quirúrgico; sin embargo, las crisis de dolor óseo disminuyen y desaparecen después del primer año, al tiempo que se detiene la osteopenia y disminuye el riesgo de fracturas. En la actualidad se están llevando a cabo investigaciones con bisfosfonatos, como tratamiento coadyuvante de la reconstrucción ósea.

El registro relativo de la calidad de vida es un concepto reciente, que se involucra de manera conveniente en el juicio de la evolución de las enfermedades crónicas. SF-36, un registro internacional para enfermedades crónicas ha puesto de relieve cómo la mejoría de los parámetros clínicos en la EG se refleja en mejoría del rendimiento y el desempeño físico, del dolor, la percepción general de salud, la vitalidad, el funcionamiento social, el desempeño emocional y la salud mental.

La terapia de reemplazo con imiglucerasa no está exenta de efectos indeseables, pero su frecuencia e intensidad son menores. Se describen reacciones de hipersensibilidad, urticaria, prurito, angioedema y alrededor de $15 \%$ de los pacientes desarrollan anticuerpos tipo $\mathrm{IgG}$ en los primeros seis meses. Otras manifestaciones menores son lumbalgia, edema periférico transitorio, náusea y vómito.

Sin duda, el costo es la mayor limitante para la terapia de reemplazo con imiglucerasa, pero la comprobada eficacia del tratamiento en los sujetos con EG, ofrece una promesa de nueva esperanza para todas las personas afectadas por enfermedades huérfanas en el mundo entero.

\section{Agradecimientos}

Al servicio de Patología y al personal de Enfermería y administración del Hospital de San José.

\section{Lecturas recomendadas}

Charrow J, Anderson HC, Kaplan P, et al. The Gaucher registry: demographics and disease characteristics of 1698 patients with Gaucher disease. Arch Intern Med. 2000; 160: 2835-43.

Giraldo P, Pocovi M, Pérez-Calvo J, et al. Report of the spanisch Gaucher's disease registry: clinical and genetic characteristics. Heamatologica. 2000; 85: 792-9.

Pérez-Calvo J, Bernal M, Giraldo P, et al. Co-morbidity in Gaucher's disease: results of a natinowide enquiry in Spain. Eur J Med Res. 2000; 5: 231-5.

Elstein D, Abrahamov a, Hadas-Halpern I, Zimran A. Recommendations for diagnosis, evaluation and monitoring of patients with Gaucher disease. Arch Intern Med. 1999; 159: $1254-5$.

Charrow J, Esplin JA, Griggle TJ, et al. Gaucher disease: recommendations on diagnosis, evaluation and monitoring. Arch Intern Med. 1998; 158: 1754-60.

Pérez-Calvo J, Giraldo P, GiraltM. Type I Gaucher's disease: clinical, evolutive and therapeutic features in 8 cases. Sangre (Barc). 1994; 39: 3-7.

Beighton J, Sacks S. Bone involvement in Gaucher disease. En Deskink RJ, Gatts, Grabowski GA eds. Gaucher Disease: a century of deliniation and reseach. Proceedings of the First International Symposium on Gaucher Disease. New York. NY Alan R Liss Inc. 1982; 107-129.

Herman G, Shapiro RS. Abdelwahab f, et al. MR imaging in adult with Gaucer disease Type 1. Evaluation of marrow involvement and disease activity. Skeletal Radiol 1993; 22: 247251.

Esplin JA, Mc Pherson EJ. Treatment of bone complication in patients with Gaucer disease. Gaucher Clinical Perspectives. 1994; 2: 7-11

Pastores GM, Sibille A, Grabowski GA. Enzyme therapy in Gaucher Disease Type 1. Dosage efficacy and adverse effects in 33 patients treated for 6 to 24 months. Blood. 1993; 32: 40816.

Niederau C, Holderer A, Heintges T, Stronhmeyer G. Gucocerebrosidase for treatment of Gaucher Disease. First longterm results. J Hepatol. 1994; 21: 610-7.

Rosenthal D, Smith MW, Goodsitt M, Doppelt S. Bone and bone marrow changes in Gaucher Disease. Evaluation in cuantitative MR. Radiology. 1989; 170: 143-6.

Mankin H, Dopplet S, Rosemberg A, Barranger J. Metabolic bone disease in patients with Gaucher disease. En: Avioli L, Krane S. eds. Metabolic bone disease and clinically related disorders. WB Saunders, 1990.

Grabowski G. Enzimology, Genetics and treatment in Gaucher disease. En: Harris H, Hirsch K. eds. Advances in Human Genetics. New York Plenum Press. 1993.

Bimal T, Latham T, Grabowski G. Gaucher disease: molecular heterogenety and phenotype-genotype correlations. Am J Hum Genet. 1989; 45: 212-25.

Sidranski E, Shaoji T, Martin B, Stubblefield B. DNA mutation analysis of Gaucher patients. Am J Med Genetics. 1992; 42: 331-6. 